\title{
Neurogenic hyperpyrexia following acute traumatic spinal cord injury. A Systematic Review
}

\author{
Panagiotis Korovessis* \\ Chief and Chair, Orthopaedic Department, General Hospital, Patras Greece
}

\begin{abstract}
Study Design: Systematic review.

Objective: To report the incidence, pathogenesis, treatment options and outcomes related to neurogenic hyperpyrexia following acute traumatic spinal cord injury (SCI).

Methods: A systematic review was performed on hyperpyrexia secondary to acute traumatic SCI in adult patients. A literature search was performed using PubMed and available literature.

Results: Using the headings terms "Spinal Cord Injury" and "Fever" and after removing duplicates, 292 articles were collected independently of the number of cases included. Papers with fever of other etiology than neurogenic hyperpyrexia were subsequently excluded. In this last search 9 original articles were selected, from which only 4 fulfilled the criteria for this systematic review. Cervical was much more often than thoracic SCI associated with hyperpyrexia. Although the incidence of fever of all origins after SCI averaged 50.5\%, (range 22.5 to $71.7 \%$ ) the incidence of neurogenic hyperpyrexia in patients sustained acute SCI averaged $8.0 \%$, (range 2.6 to 27.8\%). ASIA A SCI had a higher incidence of hyperpyrexia than ASIA B to D incomplete SCI injuries. The pathogenesis of so-called "neurogenic hyperpyrexia" following reported acute SCI is not thoroughly understood, and mostly cases have been. Few methods for treatment of hyperpyrexia have been suggested including steroids, cooling, combined steroids and hypothermia and endovascular cooling
\end{abstract}

Conclusion: Neurogenic hyperpyrexia is a relatively common clinical entity following acute SCI. However, there is little literature to help physicians prevent or treat this potential fatal condition. Further studies with larger sample sizes, focusing on incidence rate, clinical outcomes, and pathogenesis of neurogenic hyperpyrexia following acute traumatic SCI are needed. The results of this systematic review that are based on very few clinical studies suggest further research with controlled clinical trials.

\section{Introduction}

Spinal cord injury (SCI) is often devastating for the quality of life in injured individuals. While contemporary treatment of SCI, that includes both operative and rehabilitation has lessened its associated morbidity and mortality, there remains place for improvement of outcomes.[1]

Fever during hospitalization of patients with orthopaedic diseases is not uncommon, however hyperpyrexia, is rather rare. Among the causes of hyperpyrexia are malignant neuroleptic syndrome, cholinesterase deficiency, drug fever and central fever. [2,3] The common non-infectious causes should always be excluded and fever due to SCI or QUAD fever may be considered. The pathogenesis of QUAD fever is unclear but it could be attributed to autonomic dysfunction and temperature dysregulation.

The objective of this review was to report on the incidence of and the possible pathogenesis of hyperpyrexia associated SCI, or QUAD fever, the clinical outcomes and consequences of Quad fever of neurogenic origin in acute traumatic cervical and upper thoracic spinal cord injury as well as the applied treatments.

\section{Methods}

\section{Study Search}

A systematic review of the literature on hyperpyrexia and SCI was performed using PubMed (MEDLINE). No restrictions were placed on publication date and language. Utilizing PubMed, the following Medical Subject Headings terms were entered: "Spinal Cord Injuries", and "Fever". After removing duplicates, 292 articles were collected in the period from 1899 to 2019 . Since in these articles, there were papers with fever of other etiology than neurogenic hyperpyrexia, an additional search was made with the following terms in the same database: "spinal cord injury," "hyperpyrexia". In this last search 9 original articles were selected, from which only 4 fulfilled the criteria for this systematic review (Figure 1).

\section{Inclusion and Exclusion Criteria}

The primary requirement for inclusion was the description of one or more cases of a hyperpyrexia episode $>40.8^{\circ} \mathrm{C}$ of unknown etiology following SCI. For the purposes of this review, we focused on the reports that defined a hyperpyrexia. Cases that presented unidentifiable fever after SCI in addition to other associated events were included. Only four results were found that met our inclusion criteria. Studies including pediatric cases ( $<18$ years of age) were excluded.

${ }^{\star}$ Correspondence to: Panagiotis Korovessis $\mathrm{MD}, \mathrm{PhD}$, Chief and Chair, Orthopaedic Department, General Hospital, Patras Greece, E-mail: Korovessis@ agandreashosp.gr

Key words: spinal cord injury, hyperpyrexia, pathogenesis, treatment

Received: June 03, 2019; Accepted: June 12, 2019; Published: June 17, 2019 
292 articles retrieved in May 2019 from the literature

Period 1899 to 2019

Search term: Spinal Cord Injury" \& "Fever"
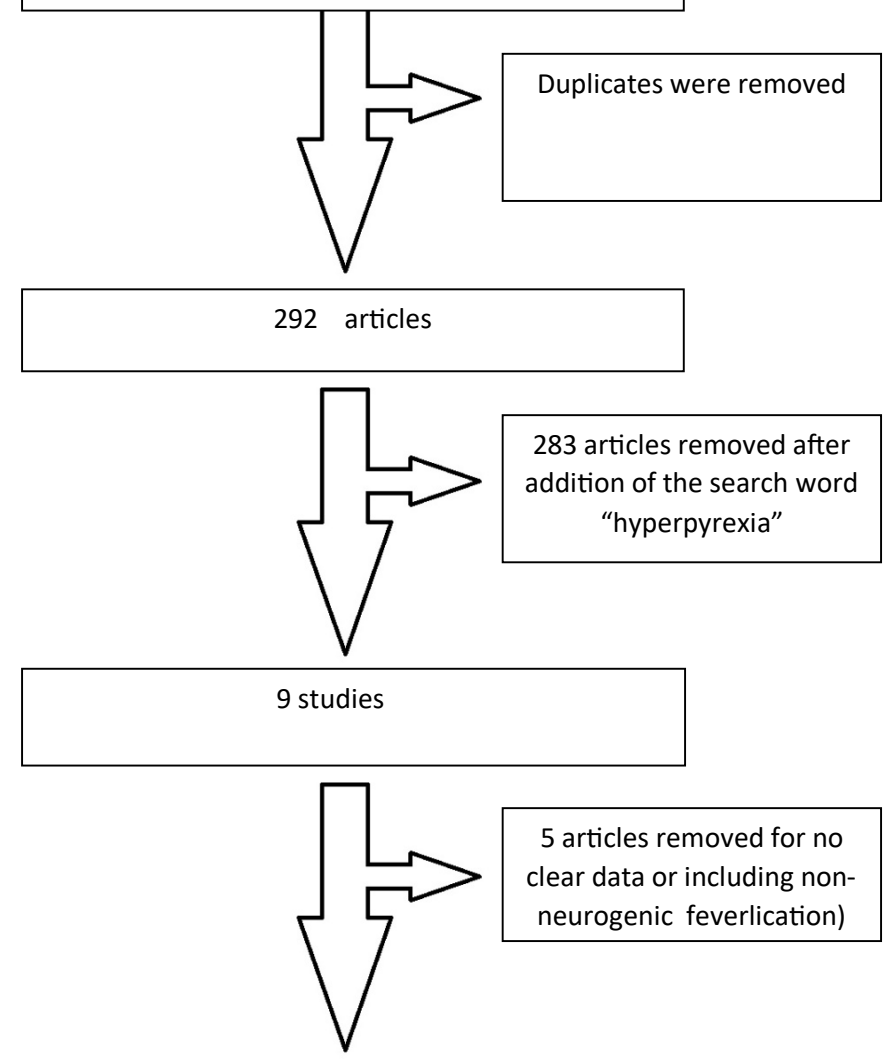

4 studies (17 patients) included because meeting inclusion criteria assessed for eligibility

15 studies with 192 patients who received TMC were finally enrolled in the specific analysis (eg. correction, mesh related complication).

Figure 1. Allocation chart

\section{Definition and Pathology}

In a SCI patient, neurogenic fever that is rare, may be due to "quad fever" that is an extreme elevation in body core temperature $>40.8^{\circ} \mathrm{C}$ with uppermost reported limit $44.8^{\circ} \mathrm{C}$ [4]. in a patient with acute SCI. [5].

Patients with high cervical SCI are at "high risk" for development of hyperpyrexia. These patients are frequently quadriplegic, although rarely it has been described in the paraplegic with a mid-level or higher thoracic spine injury [6,7].

In severe SCI, the primary injury damages spinal cord neural tissue, causing loss of neurological function below the level of cord lesion but not rarely leaves areas of intact cord intact as in incomplete SCI. A secondary autodestructive process [8] follows with hemorrhage and increasing edema, leading to infarction of cord tissues. This aggravates spinal cord damage and further impairs neural transmission $[9,10]$. Researchers believe that if this secondary spinal cord damage could be arrested, the chances of functional neurological recovery could be enhanced [4]. These cases with SCI usually have no identified cause of hyperthermia other than the autonomic central neurogenic dysfunction.

Severe autonomic dysfunction can result in thermodysregulation, as well as neurogenic shock, cardiac arrhythmias, orthostatic hypotension, autonomic dysreflexia, and hyperhidrosis [8]. Patients with quadriplegia, who developed hyperpyrexia, have historically fatal outcome. Although antipyretics are commonly used to treat fever of different etiologies and are generally efficacious, they are ineffective in treating the hyperpyrexia seen in this severe autonomic thermodysregulation [8-10].

Hypothalamus autonomically controls body temperature [2,7], in order the central regulatory centers to maintain body temperature within normal limits by utilizing cooling mechanisms to counteract endogenous heat production [11]. When patients suffer from upper cervical SCI, the regulatory centers may be disrupted, resulting in a pathophysiological response to temperature control [5]. Also, reduced blood flow to the brain, a side effect of hyperpyrexia itself, can damage central homeostatic mechanisms, further compromising the efficacy of cooling processes [12-14]. These effects can result in excessive heat production and increased body temperature.

Cellular damage has been documented to occur upon exposure to temperatures of $40-41.8 \mathrm{C}$. The effects include protein denaturation, growth inhibition, and alterations in signal transduction [12]. Hyperthermia has known effects on normal organs including lesions in the central nervous system, kidney, heart, liver, and bone marrow. Systemic effects include coagulopathy, hypovolemia, acute tubular necrosis, abnormal liver enzymes which may progress to severe liver necrosis, brain edema, extensive neuronal loss and gliosis, and intraparenchymal haemorrhage in the adrenal gland. Haematological effects include bone marrow suppression resulting in thrombocytopenia, as well as intravascular hemolysis $[12,14]$.

\section{Treatment in hyperpyrexia patients with SCI}

Steroids: In last few years there was enthusiasm in the literature for the beneficial effects of parenteral steroids following SCI in animals and more recently this beneficial effect was justified in humans [1524]. However, some researchers supported that the evidence for use of steroids in SCI was weak [25,26] Steroid administration, was considered a treatment of choice for human SCI and, extending over a decade (1977-1987), steroids were widely used. [27] The dosing regimen of dexamethasone used here was developed using information from earlier laboratory studies, $[28,29]$ which showed that its administration preserved intracellular potassium, reduced tissue damage, and was correlated with better neurological recovery. Based on previous laboratory studies, some authors administered steroids to their patients with SCI and hyperpyrexia for 11 days with subsequent cessation of fever on the $18^{\text {th }}$ day [20].

Cooling: Cooling the injured spinal cord to enhance recovery of neurological function has got increased clinical (humans) and investigative (animals) interest by the researchers [30,31]. Beneficial effects of cooling on the injured spinal cord in animals was supported 
by several authors. [17,32-43] The authors of a review, [31] showed that local spinal cord cooling had been used in patients with neurologically complete (ASIA A) SCI.

The authors of a recent prospective clinical study [44] performed on the basis of a protocol a combined approach with intravenously administrated steroids, decompressive surgery, and local cooling of the injured spinal cord, targeting to preserving as much as possible viable neural tissue and subsequently at least theoretically improving functional recovery in patients with complete SCI. The authors reported that the combined treatment offered these tetraplegic patients better recovery than might have been expected had decompression alone with/without steroids had been used [44].

The benefit of steroid treatment for SCI has been debated in the last decade, but these authors [44] supported that research into the effects of cord cooling should be expanded. Given that the optimal neuroprotective temperature after acute trauma has not yet been defined, and may well be below that which is considered safely approachable through systemic cooling, methods that allow for the early attainment of such a temperature locally should be further explored.

Combined steroid and hypothermia: Several papers reported in the subject "cooling" the spinal cord following acute SCI to enhance recovery of neurological function. Beneficial effects of local spinal cord cooling were shown in experiments [32-34,37,38-43] and patients with complete SCI $[40,45,46]$ Combined steroid and hypothermia therapy was administered to $51 \%$ of patients.[40] The rate of neurological improvement in some form was $54 \%$, the ambulation rate was $14 \%$, and the 1 -year mortality rate was $13 \%$. was administered to $51 \%$ of patients. [40] The rate of neurological improvement even little in some form was $54 \%$, the ambulation rate was $14 \%$, and the 1 -year mortality rate was $13 \%$. [40]

In a recent review, [44] the investigators felt that spinal cord cooling could be beneficial in the treatment of the injured spinal cord but that the optimal cooling temperature might be lower than what is feasible through systemic hypothermia. The authors used local spinal cord hypothermia, [44] allowing for more profound selective cooling of injured tissue while avoiding potential complications of deep general hypothermia. An equipment for localized extradural cord hypothermia has been developed by others.[47]

In a study of delayed cooling in animals (dogs), the investigators [44] showed that the best motor recovery occurred in dogs, whose traumatized spinal cords were cooled for a duration of 4 hours instead of 1-18 hours. [47] The same group of researchers also showed that after severe SCI, combining steroid agents and local spinal cord cooling at a central cord temperature of around $17^{\circ} \mathrm{C}$ produced better neurological motor recovery than conservative treatment or the single use of either.[48]

A 2008 literature review noted that "local hypothermia was actively studied already in the 1970s in human acute traumatic SCI, but no case series of this intervention has been published since 1984.[49] Late recovery following spinal cord injury may be expected, therefore it is meaningful, that the long follow-up is relevant because recovery after SCI may occur years after the injurious event. [50]

Endovascular cooling: The use of endovascular cooling in the management of severe life threatening hyperthermia in patients with cervical SCI may be an useful intervention [51].

\section{Discussion}

A frequency of neurogenic fever is approximately one per 2025 patients who sustain an acute SCI; however, despite the relative frequency of this condition, there is little in the scientific literature to help physicians prevent or treat it. Several case reports have presented the hyperpyrexia that associates acute spinal cord injury, while there are few reports on the differential diagnosis of fever of different pathologies in patients with acute SCI.

Following high cervical SCI, the resulted autonomic dysfunction may be manifested as thermodysregulation. There are 3 categories of thermodysregulation [52]. Poikilothermia is the best known in the first category, which is related to hypothermia resulting from prolonged cold exposure. The second category includes "quad fever," which refers to fever without an infectious basis that appears in the first several weeks to months after cervical SCI. The third is exercise-induced fever. All these three conditions may have devastating and lethal sequelae for the patient $[53,54]$.

"Malignant hyperthermia" that is a rare fatal genetic disorder in which patients develop elevated body temperature, increased muscle metabolism, muscle rigidity, rhabdomyolysis, acidosis, and cardiovascular instability and is linked with certain anesthetic agents [55].

Sugarman [56] described quad fever in individuals with tetraplegia and occasionally in those with high paraplegia. Quad fever is defined as an early phenomenon in patients with incomplete cervical SCI. These patients had fever that often exceeds $40^{\circ} \mathrm{C}$, fever that is encountered later in their courses. Physicians should be aware that Quad fever is considered only after all infectious or inflammatory causes have been ruled out.

Fever that occurs because of hyperthermia is often characterized by an elevation in body temperature at levels above $37 \cdot 7^{\circ} \mathrm{C}[49,57,58]$. In patient's wo are staying in the intensive care, fever is associated with poor outcome in up to $70 \%$ of the patients with or without bacterial infections. The most important noninfectious causes of severe hyperthermia are heat stroke, malignant hyperthermia, neuroleptic malignant syndrome, thromboembolism, thermoregulatory dysfunction, and medication-related fever, which are caused by failure of thermoregulation. These situations are often associated with severe systemic complications and finally death $[55,56]$.

Thyrotoxicosis may also cause increased thermogenesis [59], When fever is associated with SCI, hyperpyrexia occurs at any period e.g. during the acute phase following trauma, during the hospital stay, or after discharge [58].

In a systematic review, Savage, et al. reported a fever of any reason in patients with SCI ranging from 22.5 to $71.7 \%$, while the reported incidence of neurogenic fever was significant lower ranging from 2.6 to $27.8 \%$ [60].

The same review showed that cervical and thoracic spinal cord injuries were more commonly associated with fever than lumbar injuries. In addition, complete injuries had a higher incidence of fever than incomplete injuries [60].

Colachis, et al. Otis reported that all patients suffering from SCI at the levels T4-T6 that corresponds to the major splanchnic sympathetic plexus resulted in autonomic dysregulation[49], and thus these patients with traumatic upper thoracic and cervical SCI are also more susceptible to core body temperature changes from alterations in the 
external environment [49]. This latter is important for predicting and anticipating patients who may be at high risk for thermodysregulation.

Neurogenic shock is a form of distributive shock that involves loss of peripheral vasomotor control especially noticeable in cervical injuries [61]. A decrease in vascular resistance is associated with vascular dilatation and pooling of blood in peripheral vascular beds. Also, loss of sympathetic vascular tone causes warm, dry skin and bradycardia after cervical SCI. Plasma volume expansion is the mainstay therapy in these patients. The amount of fluid administered is based on improvement of clinical signs, particularly blood pressure, pulse pressure, and heart rate. Central venoupressure and urinary output also provide indications of restoration of vital organ perfusion but only at the macrocirculatory level. Fluid resuscitation eventually restored global hemodynamic parameters; however, restoration of microcirculation might have been inadequate. On the other hand, inflammation has a significant pathophysiologic role in renal ischemia and reperfusion injury. Also, fever is an important manifestation of inflammation.

There are several mechanisms by which targeted temperature management may improve neurological outcome when used after reperfusion. Hypothermia reduces the cerebral metabolic rate for oxygen $\left(\mathrm{CMRO}_{2}\right)$ by $6 \%$ for every $1^{\circ} \mathrm{C}$ reduction in brain temperature $>28^{\circ} \mathrm{C}$. This effect is partly due to reduced normal electrical activity [62]. Targeted temperature management is thought to suppress many of the chemical reactions associated with reperfusion injury. These reactions, as mentioned previously, are associated with hyperpyrexia and include free radical production, excitatory amino acid release, and calcium shifts, which can in turn lead to mitochondrial damage and apoptosis. Hypothermia attenuates pro-apoptotic signals, such as cytochrome c release, Fas and Bax up-regulation, and caspase activation and activates anti-apoptotic mechanisms, such as the Erk1/2 pathway and the Akt pathway [63].

Hyperpyrexia, following SCI can potentially compromise functional outcome and exacerbate tissue damage. Accordingly, steps should be taken to prevent detrimental hyperpyrexia following SCI [64].

In ICU patients, single fever episodes ranging from $38.9^{\circ} \mathrm{C}$ to $41.1^{\circ}$ $\mathrm{C}$ that disappears spontaneously within 24 hours are almost always noninfectious in nature and are most commonly caused by blood/blood products transfusion, insertion/removal of devices, or manipulation of a colonized/infected mucosal surface [65]. Some clinical studies showed that hospital-acquired sinusitis is a frequent cause of fever with unknown origin in patients with orotracheal intubation and critically ill patients on mechanical ventilation [66]. In addition, sputum production is increased in patients with cervical SCI [67].

Patients with cervical SCI are prone to atelectasis, especially at the basal side of their lungs, that subsequently may cause fever, especially in the early postoperative period. However, such extremely high temperatures in these patients could not be explained solely by atelectasis $[68,69]$. Twenty-eighty percent of the patients admitted suffering from acute cervical SCI had fatal complications caused by persistent hyperthermia of unknown origin [70]. Fever is associated with poor outcome in up to $67 \%$ of ICU patients with or without infection [71].

A literature review revealed very few reports of quad fever and its pathophysiologic mechanisms are poorly understood.

Therapeutic hypothermia protocols are utilized to induce lower body temperatures after cardiac arrest for neuroprotection, and to treat intractable intracranial hypertension.
However, a hypothermic protocol is not routinely used to treat hyperpyrexia. Literature search revealed only one previous study where an external cooling device was used to achieve normothermia in a hyperthermic patient [11].

Although the protocol was successful in inducing lower body temperatures via this noninvasive device, it was not used to treat "quad fever," but rather neuroleptic malignant syndrome.

There is one report of two cases which used an invasive endovascular cooling device to treat "quad fever." In one of the cases, the device normalized the patient's body temperature within $5 \mathrm{~h}$, but the patient later died as a result of catheter related deep vein thrombosis, a complication known to occur with invasive intravenous cooling devices. In the second patient, the cooling device was unsuccessful in controlling body temperature [72].

Conclusively, before a diagnosis of neurogenic hyperthermia can be made, a detailed systematic search for infection and other febrile causes local as abscesses, osteomyelitis etc., and systematic as urinary, blood etc. and noninfectious causes deep vein thromboses, pulmonary emboli, should be undertaken and rule out. It was reported that although an extensive methodology is undertaken, neurogenic fever is likely to remain a diagnosis by exclusion [73]. Awareness of this little known condition could help in avoiding unnecessary antimicrobial therapy and in more accurate prognostication

The paucity of research underscored by this review demonstrates the need for further studies with larger sample sizes, focusing on the incidence rate, clinical outcomes, and pathogenesis of neurogenic fever following acute traumatic SCI.

\section{References}

1. Amar AP, Levy ML (1999) Surgical controversies in the management of spinal cord injury. J Am Coll Surg 188: 550-566. [Crossref]

2. Cunha BA, Shea KW (1996) Fever in the intensive care unit. Infect Dis Clin North Am 10: 185-209. [Crossref]

3. Cunha BA (1999) Fever in the intensive care unit. Intensive Care Med 25: 648-651. [Crossref]

4. Tator CH, Fehlings MG (1991) Review of the secondary injury theory of acute spinal cord trauma with emphasis on vascular mechanisms. J Neurosurg 75: 15-26. [Crossref]

5. Lee-Chiong T, Stitt J (1995) Disorders of temperature regulation. Comprehensive Therapy 21: 697-704.

6. Montgomerie J (1997) Fevers in patients with spinal cord injuries. Clinical Infectious Diseases 25: 1285-1290.

7. Sugarman B (1982) Fever in recently injured quadriplegic persons. Arch Phys Med Rehabil 63: 639-640.

8. Allen AR (1911) Surgery of experimental lesion of spinal cord equivalent to crush injury of fracture dislocation of spinal column: a preliminary report. JAMA 57: 878-880.

9. Janssen L, Hansebout RR (1989) Pathogenesis of spinal cord injury and newer treatments. A review. Spine (Phila Pa 1976) 14: 23-32. [Crossref]

10. Oyinbo CA (2011) Secondary injury mechanisms in traumatic spinal cord injury: a nugget of this multiply cascade. Acta Neurobiol Exp (Warsz) 71: 281-299.

11. Ulger F, Dilek A, Karakaya D, Senel A, Sarihasan B (2009) Fatal fever of unknown origin in acute cervical spinal cord injury: five cases. J Spinal Cord Med 32: 343-348.

12. Storm C, Gebker R, Kru" ger A, Nibbe L, Schefold J, et al. (2009) A rare case of neuroleptic malignant syndrome presenting with serious hyperthermia treated with a non-invasive cooling device: a case report. J Med Case Reports 3: 6170.

13. Leprock J (2003) Cellular effects of hyperthermia: relevance to the minimum dose for thermal damage. Int J Hyperthermia 19: 252-266.

14. Fajardo L (1984) Pathological effects of hyperthermia in normal tissues. Cancer Research 44: 4826s-4835s. 
15. Albin MS, White RJ, Yashon D, Harris LS (1969) Effects of localized cooling on spinal cord trauma. J Trauma 9: 1000-1008. [Crossref]

16. Black P, Markowitz RS (1976) Experimental spinal cord injury in monkeys: comparison of steroids and local hypothermia. Surg Forum 22: 409-411.

17. Campbell JB, DeCrescito V, Tomasula JJ, Demopoulos HB, Flamm ES, et al. (1973) Experimental treatment of spinal cord contusion in the cat. Surg Neurol 1: 102-106. [Crossref]

18. Eidelberg E, Staten E, Watkins CJ, Smith JS (1976) Treatment of experimental spinal cord injury in ferrets. Surg Neurol 6: 243-246. [Crossref]

19. Green BA, Kahn T, Klose KJ (1980) A comparative study of steroid therapy in acute experimental spinal cord injury. Surg Neurol 13: 91-97.

20. Hansebout RR, Kuchner EF, Romero-Sierra C (1975) Effects of local hypothermia and of steroids upon recovery from experimental spinal cord compression injury. Surg Neurol 4: 531-536.

21. Lewin MG, Pappius HM, Hansebout RR (1972) Effects of steroids on edema associated with injuries of the spinal cord. In Reulen HG, Schürmann K (Eds) Steroids and Brain Edema. Berlin: Springer-Verlag pp. 101-112.

22. Bracken MB (2012) Steroids for acute spinal cord injury. Cochrane Database Syst Rev 1: CD001046.

23. Bracken MB, Shepard MJ, Collins WF Jr, Holford TR, Baskin DS, et al. (1992) Methylprednisolone or naloxone treatment after acute spinal cord injury: 1-year followup data. Results of the second National Acute Spinal Cord Injury Study. J Neurosurg 76: 23-31. [Crossref]

24. Bracken MB, Shepard MJ, Holford TR, Leo-Summers L, Aldrich EF, et al. (1997) Administration of methylprednisolone for 24 or 48 hours or tirilazad mesylate for 48 hours in the treatment of acute spinal cord injury. Results of the Third National Acute Spinal Cord Injury Randomized Controlled Trial. JAMA 277: 1597-1604.

25. Hurlbert RJ (2001) The role of steroids in acute spinal cord injury: an evidence-based analysis. Spine (Phila Pa 1976) 26 (24 Suppl): S39-S46.

26. Hurlbert RJ, Moulton R (2002) Why do you prescribe methylprednisolone for acute spinal cord injury? A Canadian perspective and a position statement. Can J Neurol Sci 29: 236-239.

27. Tator CH, Rowed DW (1979) Current concepts in the immediate management of acute spinal cord injuries. Can Med Assoc J 121: 1453-1464. [Crossref]

28. Hansebout RR, Lewin MG, Pappius HM (1972) Evidence regarding the action of steroids in injured spinal cord. In Reulen HG, Schürmann K (Eds) Steroids and Brain Edema. Berlin: Springer-Verlag pp. 153-155.

29. Lewin MG, Hansebout RR, Pappius HM (1974) Chemical charac $\neg$ teristics of traumatic spinal cord edema in cats. Effects of ste $\neg$ roids on potassium depletion. $J$ Neurosurg 40: $65-75$.

30. Janssen L, Hansebout RR (1989) Pathogenesis of spinal cord injury and newer treatments. A review. Spine (Phila Pa 1976) 14: 23-32. [Crossref]

31. Kuchner EF, Mercer ID, Pappius HM, Hansebout RR (1976) Experimental spinal cord injury: effects of steroids and/or cooling on edema, electrolytes, and motor recovery. In Pappius HM, Feindel WF (Eds) Dynamics of Brain Edema: Proceedings of the Third International Workshop on Dynamic Aspects of Cerebral Edema, Montreal, Canada, June 25-29, 1976. Berlin: Springer-Verlag pp.315-322.

32. Albin MS, White RJ, Acosta-Rua G, Yashon D (1968) Study of functional recovery produced by delayed localized cooling after spinal cord injury in primates. $J$ Neurosurg 29: 113-120.

33. Albin MS, White RJ, Locke GS, Massopust LC Jr, Kretchmer HE (1967) Localized spinal cord hypothermia - anesthetic effects and application to spinal cord injury. Anesth Analg 46: 8-16.

34. Albin MS, White RJ, MacCarty CS (1963) Effects of sustained perfusion cooling of the subarachnoid space. Anesthesiology 24: 72-80.

35. Black P (1976) Recovery of spinal cord trauma: comparison of hypothermia and normothermic perfusion with and without durotomy. Congress of Neurological Surgeons Annual Meeting Proceedings. New Orleans, LA.

36. Black P, Shepard RH Jr, Markowitz RS (1975) Spinal cord injury in monkey: comparison of normothermic and hypothermic perfusion. Congress of Neurological Surgeons Annual Meeting Proceedings, Atlanta, GA.

37. Ducker TB, Hamit HF (1969) Experimental treatments of acute spinal cord injury. $J$ Neurosurg 30: 693-697. [Crossref]
38. Kelly DL Jr, Lassiter KR, Calogero JA, Alexander E Jr (1970) Ef $\neg$ fects of local hypothermia and tissue oxygen studies in experi-mental paraplegia. J Neurosurg 33: 554-563.

39. Kuchner EF, Hansebout RR (1976) Combined steroid and hypothermia treatment of experimental spinal cord injury. Surg Neurol 6: 371-376.

40. Negrin J Jr (1963) Direct regional hypothermia of the brain by ex $\neg$ travascular intracranial perfusion. Rev Neurol (Paris) 108: 923-927.

41. Negrin J Jr (1960) Prévention des lésions de la moelle épiniére par l'hypothermia régionale extravasculaire. Rev Neurol (Paris) 106: 725-729.

42. Thienprasit P, Bantli H, Bloedel JR, Chou SN (1975) Effect of delayed local cooling on experimental spinal cord injury. $J$ Neurosurg 42: 150-154. [Crossref]

43. Wells JD, Hansebout RR (1978) Local hypothermia in experimental spinal cord trauma Surg Neurol 10: 200-204. [Crossref]

44. Hansebout RR, Hansebout CR (2014) Local cooling for traumatic spinal cord injury: outcomes in 20 patients and review of the literature. J Neurosurg Spine 20: 550-561.

45. Hansebout RR (1982) A comprehensive review of methods of improving cord recovery after acute spinal cord injury, in Tator CH (ed): Early Management of Acute Spinal Cord Injury. Seminars in Neurological Surgery Series. New York: Raven Press, pp 181-196.

46. Romero-Sierra C, Hansebout R, Sierhuis A, Lewin M (1974) A new method for localised spinal-cord cooling. Med Biol Eng 12: 188-193. [Crossref]

47. Wells JD, Hansebout RR (1978) Local hypothermia in experimental spinal cord trauma Surg Neurol 10: 200-204. [Crossref]

48. Hansebout RR, Kuchner EF, Romero-Sierra C (1975) Effects of local hypothermia and of steroids upon recovery from experimental spinal cord compression injury. Surg Neurol 4: 531-536.

49. Colachis SC III, Otis SM (1995) Occurrence of fever associated with thermoregulatory dysfunction after acute traumatic spinal cord injury. Am J Phys Med Rehabil 74: 114 119.

50. McDonald JW, Becker D, Sadowsky CL, Jane JAS Sr, Conturo TE, Schultz LM (2002) Late recovery following spinal cord injury. Case report and review of the literature. $J$ Neurosurg 97: 252-265.

51. Tripathy S, Whitehead CF (2011) Endovascular cooling for severe hyperthermia in cervical spine injury. Neurocrit Care 15: 525-528.

52. Krassioukov AV, Karlsson AK, Wecht JM, Wuermser LA, Mathias CJ, et al. (2007) Assessment of autonomic dysfunction following spinal cord injury: rationale for additions to International Standards for Neurological Assessment. J Rehabil Res Dev 44: 103-112.

53. Randall WC, Wurster RD, Lewin RJ (1966) Responses of patients with high spinal transection to high ambient temperatures. J Appl Physiol 21: 985-993. [Crossref]

54. Khosla R, Guntupalli KK (1999) Heat-related illnesses. Crit Care Clin 15: 251-263. [Crossref]

55. Denborough M (1998) Malignant hyperthermia. Lancet 352: 1131-1136. [Crossref]

56. Sugarman B, Brown D, Musher D (1982) Fever and infection in spinal cord injury patients. JAMA 248: 66-70. [Crossref]

57. Unsal-Delialioglu S, Kaya K, Sahin-Onat S, Kulakli F, Culha C, et al. (2010) Fever during rehabilitation in patients with traumatic spinal cord injury: analysis of 392 cases from a national rehabilitation hospital in Turkey. J Spinal Cord Med 33: 243-248. [Crossref]

58. McKinley W, McNamee S, MeadeM, Kandra K, Abdul N (2006) Incidence, etiology, and risk factors for fever following acute spinal cord injury. J Spinal Cord Med 29: 501-506.

59. Burch HB, Wartofsky L (1993) Life-threatening thyrotoxicosis. Thyroid storm Endocrinol Metab Clin North Am 22: 263-277.

60. Savage EK, Oleson VC, Schroeder DG, Sidhu SG, Vaccaro RA (2016) Neurogenic Fever after Acute Traumatic Spinal Cord Injury: A Qualitative Systematic Review. Global Spine J 6: 607-614.

61. Papadakos PJ (2011) Approach to shock. In: Apostolakos MJ, Papadakos PJ (Eds) The Intensive Care Manual. New York: McGraw-Hill p. 55-70.

62. Steen PA, Newberg L, Milde JH, Michenfelder JD (1983) Hypothermia and barbiturates: individual and combined effects on canine cerebral oxygen consumption. Anesthesiology 58: 527-532. 
63. Han HS, Park J, Kim J, Suk K (2012) Molecular and cellular pathways as a target of therapeutic hypothermia: pharmacological aspect. Curr Neuropharmacol 10: 80-87.

64. Yu CG, Jagid J, Ruenes G, Dietrich WD, Marcillo AE, et al. (2001) Detrimental effects of systemic hyperthermia on locomotor function and histopathological outcome after traumatic spinal cord injury in the rat. Neurosurgery 49: 152-158. [Crossref]

65. Cunha BA (1999) Fever in the intensive care unit. Intensive Care Med 25: 648-651. [Crossref]

66. van Zanten AR, Dixon JM, Nipshagen MD, de Bree R, Girbes AR, et al. (2005) Hospital-acquired sinusitis is a common cause of fever of unknown origin in orotracheally intubated critically ill patients. Crit Care 9: R583-R590.

67. Bhaskar KR, Brown R, O’Sullivan DD, Melia S, Duggan M, et al. (1991) Bronchial mucus hypersecretion in acute quadriplegia. Macromolecular yields and glycoconjugate composition. Am Rev Respir Dis 143: 640-648.
68. Winslow C, Rozovsky J (2003) Effect of spinal cord injury on the respiratory system. Am J Phys Med Rehabil 82: 803-814. [Crossref]

69. Lanig IS, Peterson WP (2000) The respiratory system in spinal cord injury. Phys Med Rehabil Clin N Am 11: 29-43, vii.vii.348. [Crossref]

70. Fatma Ulger, Ahmet Dilek, Deniz Karakaya, Alparslan Senel, Binnur Sarihasan (2009) Fatal Fever of Unknown Origin in Acute Cervical Spinal Cord Injury: Five Cases. $J$ Spinal Cord Med 32: 343-348.

71. Jun-ichi Hirata, Munehiko Ohya, Keiji Kumon (2014) Fatal hyperthermia following acute cervical spinal cord and headinjury. Crit Care \& Shock 17: 96-99.

72. Tripathy S, Whitehead C (2011) Endovascular cooling for severe hyperthermia in cervical spine injury. Neurocritical Care 15: 525-528.

73. Thompson HJ, Pinto-Martin J, Bullock MR (2003) Neurogenic fever after traumatic brain injury: an epidemiological study. J Neurol Neurosurg Psychiatry 74: 614-619.

Copyright: (C2019 Korovessis P. This is an open-access article distributed under the terms of the Creative Commons Attribution License, which permits unrestricted use, distribution, and reproduction in any medium, provided the original author and source are credited. 